\title{
Predictors of poor follow-up after bariatric surgery
}

\section{Fatores preditivos da perda de seguimento de pacientes submetidos à cirurgia bariátrica}

Giselle de Quelroz Menezes Batista Belo'; Luciana Teixeira de Siqueira'; Djalma A. Agripino Melo Filho'; Flávio Kreimer, TCBC-PE; Vânia Pinheiro Ramos'; Álvaro Antônio Bandeira Ferraz, TCBC-PE ${ }^{1}$

\section{A B S T R A C T}

\begin{abstract}
Objective: to identify predictive factors of loss of follow-up of patients submitted to Roux-en-Y gastric bypass and sleeve gastrectomy in a 48-month period. Methods: we conducted a retrospective, cohort study from January 2010 to December 2012. We analyzed thirteen variables and compared them to loss of follow-up. Results: among the 559 patients studied, there was a great reduction in the frequency (43.8\%) of the consultations from the second postoperative year on, with a significant loss in the 4th year (70.8\%). In the univariate analysis, only the variable "excess weight" was associated with loss of follow-up. The proportion of overweight (>49.95kg) was higher in the follow-up group with greater loss (>3 absences) ( $p=0.025)$. In the logistic regression, patients exposed to a greater excess weight ( $>49.95 \mathrm{~kg}$ ) presented a two-fold higher risk for loss of follow-up ( $>3$ absences) (OR=2.04, 95\% Cl 1.15-3.62; $p=0.015)$. In the univariate analysis, at the 48th postoperative month, only the variable "mesoregion of origin" was associated with loss of follow-up ( $p=0.012$ ). Conclusion: there was a progressive loss of follow-up from the second postoperative year on. Among the factors analyzed, only the variable "excess weight" greater than $49.95 \mathrm{~kg}$ in the preoperative period was associated with loss of medical-surgical follow-up. In the $48 \mathrm{th}$ month of the postoperative period, there was a higher prevalence of loss of medical-surgical follow-up for patients outside the perimeter of the city of Recife $(51 \%, p=0.052)$.
\end{abstract}

Keywords: Obesity. Bariatric surgery. Gastric Bypass. Gastrectomy. Lost to Follow-Up.

\section{INTRODUCTION}

$\mathrm{B}$ eing considered a severe health problem worldwide, obesity is affects around $13 \%$ of the world's adult population ( $11 \%$ of men and $15 \%$ of women), and can reach up to $20 \%$ in $2025^{1}$. Faced with the failure of conservative treatment after a period longer than two years, bariatric surgery is indicated as a strategic alternative for rapid weight loss, remission or improvement of comorbidities, and improvement of quality and expectancy of life $e^{2,3}$. Among the surgical techniques, Roux-en-Y gastric bypass (RYGB) has been advocated for providing excellent percentage loss of overweight, between $65 \%$ to $70 \%$, and sustainable weight loss, particularly for those with metabolic syndrome or diabetes mellitus type $2^{4,5}$. Sleeve gastrectomy (SG) has been highlighted in recent years because it presents relative technical simplicity, advantages in rapid weight loss, and lower complications rates when compared to Roux-en-Y gastric bypass ${ }^{6,7}$.

However, these techniques are not exempt from complications in the short, medium and long term.
In view of the complexity of the surgical procedure, RYGB reaches postoperative complications rates of 15 to $20 \%$, with deficiencies of proteins, vitamins and micronutrients, ulcers, stenosis, internal hernias, cholelithiasis, and inadequate weight loss and/or weight regain ${ }^{8}$. In this context, laparoscopic Sleeve gastrectomy (LSG) presents lower morbidity, but with complications that may require long-term reoperations.

Therefore, regular medical-surgical and multiprofessional follow-up is extremely important to prevent and treat complication soon ${ }^{9,10}$. The Brazilian recommendations for postoperative follow-up emphasize the regularity and importance of maintaining it, to early detect metabolic and nutritional changes, as well as to monitor weight ${ }^{11-15}$. This postoperative follow-up presents major challenges. One is to keep the patients in the protocol of consultations adopted with the surgeon or multiprofessional team ${ }^{11}$. Studies report high followup loss rates, above $49 \%$, in the first postoperative year ${ }^{9,12,16}$, but there is no consensus regarding the reasons for patients not adhering to the recommended follow-up

1 - Federal University of Pernambuco, Department of Surgery, Recife, PE, Brazil. 
protocol after bariatric surgery ${ }^{16,17}$.

Thus, our objective was to identify the predictive factors of the loss of follow-up of a cohort of patients submitted to Roux-en-Y gastric bypass and sleeve gastrectomy, in a period of 48 months. This aims to alert health professionals about the importance of investing in strategies that enhance patients' adequate follow-up, which will enable the benefits of bariatric surgery to be sustainable, improve the health of society and reduce costs, especially for the Brazilian Unified Health System (SUS).

\section{METHODS}

We conducted a retrospective cohort study with patients with obesity grades II and III submitted to surgical treatment by open Roux-en-Y gastric bypass with retention ring or laparoscopic sleeve gastrectomy, from January 2010 to December 2012. We evaluated the outcome loss of follow-up at the 1st, 3rd, 12th, 24th, 36th and 48th months, with patients being categorized into YES and NO. We excluded patients who underwent revision of bariatric surgery, pregnant women and those who died during the study period. We collected the data between 2016 and 2017, and accessed biological, socioeconomic, anthropometric and clinical-surgical variables from patients' electronic records.

\section{Technical Procedures}

Preoperative evaluation: patients visited the surgeon on two occasions in the preoperative period. In the first one, preoperative examinations were requested, including cardiological, endocrinological, pneumological, nutritional and psychological evaluations, as well as laboratory tests, upper gastrointestinal endoscopy with a search for Helicobacter pylori, total abdominal ultrasonography, and others defined according to the patient's needs. In the second, the surgeon informed the patients of the importance of adherence to the proposed treatment, in addition to signing a free informed consent form for the surgical procedure. At the end of the consultation, the surgeon and the patients jointly defined the surgical technique. After explaining the advantages and disadvantages of each procedure, the surgery was defined for each case and the date of the surgical procedure was set.
Postoperative follow-up: The first postoperative outpatient visit was scheduled for 15 days after discharge. The other consultations followed a specific protocol of the surgeon: 1st month, 3rd month, 12th months. After this period, the control began to be annual, with evaluations at the 24th, 36th and 48th months. The surgeon requested the return to the office in the times determined by the norms of the follow-up. Thus, it was the responsibility of the patient to schedule the subsequent consultation. At the time of the consultation, the surgeon recorded the patient's complaints, the pre-existing weight and preexisting comorbidities, the results of the laboratory tests, the treatment of clinical and/or surgical complications, the regularity of administration of the multivitamins, tolerance to the prescribed diet, frequency of nutritional consultations and practice of physical activity. All weight assessments in the pre- and postoperative periods were performed by the surgeon using a calibrated portable electronic scale with a $350 \mathrm{~kg}$ capacity.

We entered and stored the data in a Microsoft Office Access program spreadsheet and then transferred to Microsoft Office Excel, where we evaluated and corrected errors or inconsistencies. Subsequently, they were transferred to the SPSS software, where we carried out the analysis. Considering that not all continuous variables presented normal distribution, as evaluated by the Kolmogorov-Smirnov test, we chosen the median to summarize its values and determine intervals in the construction of the dichotomous variables. We compared proportions by Mantel-Haenszel's $X^{2}$ test, and the medians, by the Mann-Whitney $U$ test. We performed logistic regression analysis to examine the contribution of each independent variable in the loss of follow-up. In this sense, the model was adjusted to a binary result (loss of follow-up defined as $>3$ absences, and follow-up $=3$ absences), and included variables with $p<0.20$ found in the univariate analysis. We made the adjustments by a stepwise, gradual elimination of variables. We calculated adjusted odds ratios (OR) and their respective confidence intervals (95\%). We considered as significant the statistical tests with probability $<0.05$.

The Ethics in Research Committee of the Federal University of Pernambuco - CAAE: 40558315.8.0000.5208, created by resolution of the National Health Council of no 466/2012. 


\section{RESULTS}

We evaluated 559 patients (398 women and 161 men), with a median age of 35 years, predominantly between 30 and 39 years (34.1\%). More than half of the patients were married (62\%). There were 488 individuals (87.2\%) coming from the Metropolitan Mesoregion of Recife, and $52 \%$ lived in the city of Recife. As for Recife residents, $61.1 \%$ had high socioeconomic status.

The baseline BMI presented a general median of $40.76 \mathrm{~kg} / \mathrm{m}^{2}$, with the highest value for the male group $(42.27 \%, p<0.0001)$. The overall median overweight was $49.95 \mathrm{~kg}$, being higher in males $(61 \mathrm{~kg}, \mathrm{p}<0.0001)$. Most patients denied alcoholism (64.4\%), smoking (83.2\%) and comorbidities (67.6\%). Among those with at least one comorbidity, systemic arterial hypertension was the most frequent $(51.2 \%)$. The majority of subjects in the study were from the Roux-en-Y gastric bypass group $(66.5 \%)$.

In the absolute and relative frequencies of the follow-up losses, there was an increase in the absence of consultations during the 48-month period. There was a great reduction in the frequency of consultations from the second year of the postoperative period on, with a significant loss in the 4th year (70.8\%). As for the accumulated losses, these were greater for those patients who missed between two and three visits (64.9\%) (Table 1).

Table 1. Absolute and relative frequencies of patients' loss of follow-up after Bariatric Surgery $(n=559)$.

\begin{tabular}{lcc}
\hline \multicolumn{1}{c}{ Variables } & $\mathrm{n}$ & $\%$ \\
\hline Follow-up time & & \\
1 month & 63 & 11.3 \\
3 months & 55 & 9.8 \\
12 months & 130 & 23.3 \\
24 months & 245 & 43.8 \\
36 months & 355 & 63.5 \\
48 months & 396 & 70.8 \\
Accumulated absences & & \\
No absence & 29 & 5.2 \\
1 absence & 110 & 19.7 \\
2 absences & 193 & 34.5 \\
3 absences & 170 & 30.4 \\
4 absences & 47 & 8.4 \\
5 absences & 10 & 1.8 \\
\hline
\end{tabular}

In the univariate analysis, only the variable "overweight" was associated with loss of follow-up. The proportion of overweight $(>49.95 \mathrm{~kg})$ was higher in the follow-up group with greater loss $(>3)(p=0.025)$ (Tables 2 and 3).

Table 2. Comparison between biological and socioeconomic variables and the loss of follow-up within 48 months after bariatric surgery.

\begin{tabular}{|c|c|c|c|}
\hline \multirow[b]{2}{*}{ Variables } & \multicolumn{2}{|c|}{ Follow-up visits } & \multirow[b]{2}{*}{ p-value* } \\
\hline & $\begin{array}{l}\text { Loss of follow-up *** } \\
\qquad(n=57)\end{array}$ & $\begin{array}{l}\text { Follow-up } * * * * \\
\qquad(n=502)\end{array}$ & \\
\hline \multicolumn{4}{|l|}{ Age (in years) } \\
\hline$=35$ & $28(49.1 \%)$ & 256 (51.0\%) & 0.898 \\
\hline$>35$ & 29 (50.9\%) & 246 (49.0\%) & \\
\hline \multicolumn{4}{|l|}{ Gender } \\
\hline Male & $19(33.3 \%)$ & $142(28.3 \%)$ & 0.521 \\
\hline Female & $38(66.7 \%)$ & 360 (71.7\%) & \\
\hline \multicolumn{4}{|l|}{ Marital status } \\
\hline Married & $38(66.7 \%)$ & 309 (61.6\%) & 0.542 \\
\hline Other & $19(33.3 \%)$ & 193 (38.4\%) & \\
\hline \multicolumn{4}{|l|}{ Region of origin } \\
\hline Recife & 49 (86.0\%) & 439 (87.5\%) & 0.913 \\
\hline Another & $8(14.0 \%)$ & $63(12.5 \%)$ & \\
\hline \multicolumn{4}{|l|}{ City of residence } \\
\hline Recife & $27(47.4 \%)$ & 263 (52.4\%) & 0.563 \\
\hline Another & 30 (52.6\%) & 239 (47.6\%) & \\
\hline \multicolumn{4}{|c|}{ Neighborhood residence living condition stratum** } \\
\hline "High" & $16(59.3 \%)$ & $161(61.2 \%)$ & 0.993 \\
\hline "Intermediate or low" & $11(40.7 \%)$ & $102(38.9 \%)$ & \\
\hline
\end{tabular}

* Mantel-Haenszel $X^{2} ;{ }^{*}$ Only for Recife residents; ${ }^{* *}$ Follow-up absences= 3; Follow- $u$ p 3 consultations. 
Table 3. Comparison of Anthropometrical and clinical-surgical variables and follow-up loss in the period of 48 months after bariatric surgery.

\begin{tabular}{|c|c|c|c|}
\hline \multirow[b]{2}{*}{ Variables } & \multicolumn{2}{|c|}{ Follow-up visits } & \multirow[b]{2}{*}{ p-value* } \\
\hline & $\begin{array}{l}\text { Loss of follow-up } \\
\qquad(n=57)\end{array}$ & $\begin{array}{l}\text { Follow-up } \\
(n=502)\end{array}$ & \\
\hline \multicolumn{4}{|l|}{ Anthropometric } \\
\hline \multicolumn{4}{|l|}{ BMI $\left(\mathrm{kg} / \mathrm{m}^{2}\right)$ initial } \\
\hline$=40.76$ & $24(42.1 \%)$ & $255(50.8 \%)$ & 0.270 \\
\hline$>40.76$ & $33(57.9 \%)$ & $244(49.2 \%)$ & \\
\hline \multicolumn{4}{|l|}{ Initial excess weight (kg) } \\
\hline$=49.95$ & $20(35.1 \%)$ & $260(51.8 \%)$ & 0.025 \\
\hline$>49.95$ & 37 (64.9\%) & $242(48.2 \%)$ & \\
\hline \multicolumn{4}{|l|}{ Clinical Variables } \\
\hline Alcoholism & $15(26.3 \%)$ & $184(36.7)$ & 0.162 \\
\hline Smoking & $4(7.0)$ & $37(7.4)$ & 0.864 \\
\hline \multicolumn{4}{|l|}{ Comorbidities** } \\
\hline At least one comorbidity & $22(38.6 \%)$ & 159 (31.7\%) & 0.364 \\
\hline Hypertension & 29 (50.9\%) & $257(51.2 \%)$ & 0.925 \\
\hline Type II diabetes & $17(29.8 \%)$ & $146(29.1)$ & 0.970 \\
\hline Dyslipidemia & $12(21.1 \%)$ & $121(24.1 \%)$ & 0.728 \\
\hline \multicolumn{4}{|l|}{ Surgical Variables } \\
\hline \multicolumn{4}{|l|}{ Surgical technique } \\
\hline Roux-en-Y gastric bypass & 39 (68.4\%) & $333(66.3 \%)$ & 0.867 \\
\hline Sleeve gastrectomy & $18(31.6 \%)$ & 169 (33.7\%) & \\
\hline
\end{tabular}

${ }^{*}$ Mantel Haenszel $X^{2} ;{ }^{* *}$ Hypertension, type II diabetes, dyslipidemia; ${ }^{* *}$ Follow-up absences $=3$; Follow-up 3 consultations.

After adjusting for confounding factors, we found in the logistic regression model that patients exposed to a greater excess weight $(>49.95 \mathrm{~kg})$ had an approximately two-fold higher chance for loss of follow- up (>3 losses) (OR=2.04, 95\% Cl 1.15-3.62, $\mathrm{p}=0.015)$. Ethanol, which also entered the model, showed no association ( $p>0.05$ ) (Table 4).

Table 4. Logistic regression analysis of the loss of follow-up (>3) within a period of 48 months post-op.

\begin{tabular}{lccccc}
\hline \multicolumn{1}{c}{ Variable } & $\beta$ & Standard error & Wald & p-value & OR $(95 \% \mathrm{Cl})$ \\
\hline Initial excess weight $>49.95 \mathrm{~kg}$ & 0.714 & 0.293 & 5.944 & 0.015 & $2.04(1.15-3.62)$ \\
Alcoholism & -0.524 & 0.317 & 2.735 & 0.098 & $0.59(0.32-1.10)$ \\
\hline
\end{tabular}

$B M I=$ body mass index; OR= adjusted odds ratio; $C l=$ confidence interval.

In the univariate analysis performed in the 48th month of postoperative follow-up, among the biological, socioeconomic, anthropometric and clinicalsurgical variables, only the variable "mesoregion of origin" ( $p=0.012$ ) was associated with loss of follow-up, although the "city of residence" had a higher frequency for residents of the Recife metropolitan region (51\%, $\mathrm{p}=0.052$ ).

\section{DISCUSSION}

Most bariatric surgery centers have standard post-operative protocols, but loss of follow-up is a persistent problem after the first year. Postoperative adhesion benefits the patient regardless of the surgical technique used, not only for the prevention of longterm complications, but also for sustainable weight 
loss. International surveys indicate progressively low rates of adherence to scheduled appointments in the postoperative period: $50 \%$ in the first year, $30 \%$ in two years, and $<10 \%$ in ten years ${ }^{9,18,19}$.

In Brazil, despite extensive research, we found no specific studies on the rates of medical-surgical followup, only nutritional. The rates presented for adherence to nutritional follow-up varied significantly between one year (51\% and $56 \%)$, two years $(25.37 \%)$ and over two years (14.93\%) post-surgery ${ }^{12,20,21}$. These results call attention to the possibility of patients recovering their old habits, mainly with problems associated with weight.

It is noteworthy that, even though postoperative follow-up rates are within the literature, patients remain progressively absent from pre-established consultations by the surgeon. Then, it was necessary to identify the variables that predispose to loss of follow-up. Of the predictive factors analyzed, only the anthropometric variable "initial overweight" greater than $49.95 \mathrm{~kg}$ was associated with loss of follow-up, with statistical significance, diverging from the results presented by other researchers ${ }^{17,22}$. In 2011, in an analysis to assess the relationship of weight loss success with adherence to postoperative consultations of bariatric surgery among 60 obese patients, Compher et al. ${ }^{22}$ presented an average of $70 \mathrm{~kg}( \pm 27.3)$ initial overweight for the group of patients with loss of follow-up ( $p$-value $>0.05$ ). Jennings et al. ${ }^{17}$, in 2013 , presented an initial overweight value for the group with loss of follow-up of $76.4 \mathrm{~kg}(p=0.39)$. In both studies, there is concordance with the initial overweight greater than $49.95 \mathrm{~kg}$, but not statistically significant. A consensus has not yet been established in the literature, but a greater preoperative excess weight is more commonly associated with loss of follow-up ${ }^{19}$.

The variable age was not associated with loss of follow-up, as in other studies ${ }^{22,23}$. A review article published in 2016 analyzed studies that aimed to identify factors predictive of adherence and loss of follow-up after bariatric surgery. Of the 44 articles analyzed, eight presented conflicting results regarding the variable age. Some presented results with no statistical significance, others showed an association between loss of follow-up and age below 43 and 45 years ${ }^{11}$. Khorgami et al. ${ }^{9}$, in 2015, justify the statistical significance for adherence in the consultations of middle-aged adults (40 to 59 years) due to their better understanding of the importance given to health, greater stability at work, and private health plans.

The absence of association between gender and the loss of follow-up found in our study corroborates the results obtained by Vidal et al. ${ }^{16}$, Jennings et al. ${ }^{17}$, Magalhães et al..$^{20}$ and McVay et al. ${ }^{24}$, but are discordant from the results of Khorgami et al. ${ }^{9}$, which identified a significantly higher prevalence of follow-up loss in men (25.5\%).

McVay et al. ${ }^{24}$, in 2013, investigated adherence predisposing factors after Roux-en- $Y$ gastric bypass. Among the analyzed factors, married marital status was not statistically significant, although it showed a higher adherence rate $(54.6 \%, p=0.23)$. Our study also found no association between marital status and loss of followup, but married patients presented greater adherence $(66.7 \%)$, corroborating the aforementioned casuistry. Family support may be a motivator for staying in health care.

Scientific research has demonstrated an association between the loss of follow-up and the distance of the patient's home from the medical office $e^{17,23,25}$. An American study showed that individuals who lived more distant from the office $(>80 \mathrm{~km}$ ) were significantly more absent at scheduled appointments from the ninth postoperative follow-up month on, justified by the change of address, inability to drive long distances and climatic factors ${ }^{25}$. In England, Jennings et al. ${ }^{17}$, in 2013, evaluated the relationship between the distance between the patient's home and the office and the evolution of weight loss, establishing an association: the most distant residents ( $>33 \mathrm{~km}, p=0.03$ ) lost less weight due to failure to follow up. In the present study, however, there was no association between the variables of the mesoregion of origin and city of residence with loss of follow-up at 48 months. This corroborates the work presented by Sockalingam et al. ${ }^{23}(p=0,05)$, although the univariate analysis of the 48th postoperative month displayed statistical significance in the association between the loss of follow-up and the residents of the Recife metropolitan mesoregion, including the city of Recife $(p=0.011)$, more frequently for residents outside the perimeter of this municipality (between 10-74km, 51\%, p=0.052).

The body mass index in the preoperative period was not associated with the loss of follow-up, as reported in the results of Vidal et $a /{ }^{16}(p=0.182)$. Researches 
differed from the results presented. In the multivariate analysis, the highest preoperative BMI was associated with adherence to postoperative follow-up ${ }^{9}$.

Some studies focused on the effectiveness of bariatric surgery in improving or curing the various morbidities associated with obesity. However, few papers studied the association between the presence of comorbidities in the preoperative period and the loss of follow-up. Magalhães et al. ${ }^{20}$, in 2012, observed no association between the presence of comorbidities in the preoperative period and adherence to follow-up during a 12-month period. The present study corroborates this nuance, since it did not identify an association between comorbidities and loss of follow-up at 48 months, although patients with systemic arterial hypertension presented a higher frequency in the loss of followup group (50.9\%), possibly justified by the demand for other medical specialties, indirectly hampering the medical-surgical follow-up. These results differ from the publication by Khorgami et al. ${ }^{9}$, who showed in the multivariate analysis that type 2 diabetes mellitus, systemic arterial hypertension and obstructive sleep apnea are independent predictors of loss of follow-up.

The RYGB and SG surgical techniques were not associated with loss of follow-up when compared in the univariate analysis, corroborating the results found by Vidal et al. ${ }^{16}(p=0.158)$. Spaniolas et $a l .{ }^{26}$, in an attempt to identify the relationship between adherence to postsurgical consultations and loss of overweight among morbidly obese patients in the postoperative period of RYGB and SG, found a small but independent relationship between the techniques studied with postoperative adherence and weight loss.

The retrospective study has limitations. We had some difficulties regarding the revision of information sources, which we minimized by the standardization of data collection and the objective outcome definition. In addition, inconsistencies in follow-up after bariatric surgery, mainly due to the heterogeneity of methodologies, including different study designs, sample sizes, definitions and follow-up time, and types of bariatric surgery made it difficult to analyze the results 12,20 .

Assuming that bariatric surgery is not the cure for obesity, future studies on the loss of postoperative follow-up become extremely important to alert health professionals about the need to include, in routine protocols, early detection of the predisposing factors of loss of follow-up, pre and post-operative educational activities programs focused on individual patients' needs, and actively seeking those who fail in the postoperative period, as measures to increase the frequency in the consultations and obtain better results.

The analysis of the data allowed us to conclude that there was a loss of progressive follow-up of the patients in the medical-surgical consultations from the second postoperative year on. Among the factors analyzed, only the variable overweight greater than $49.95 \mathrm{~kg}$ in the preoperative period was associated with loss of medical-surgical follow-up. In the 48th month of the postoperative period, there was a higher prevalence of loss of medical-surgical follow-up for patients residing outside the perimeter of the city of Recife.

\title{
R E S U M O
}

\begin{abstract}
Objetivo: identificar os fatores preditivos da perda de seguimento de pacientes submetidos à derivação gástrica em $Y$ de Roux e gastrectomia vertical num período de 48 meses. Métodos: estudo de coorte, retrospectivo, no período de janeiro de 2010 a dezembro de 2012. Treze variáveis foram analisadas e comparadas à perda de seguimento. Resultados: entre os 559 pacientes estudados, verificou-se grande redução na frequência $(43,8 \%)$ às consultas a partir do segundo ano de pós-operatório com uma perda significativa no quarto ano (70,8\%). Na análise univariada, apenas a variável "excesso de peso" esteve associada à perda de seguimento. A proporção de excesso de peso $(>49,95 \mathrm{~kg})$ foi maior no grupo de seguimento com maior perda $(>3)(p=0,025)$. Na regressão logística, os pacientes expostos a um maior excesso de peso $(>49,95 \mathrm{~kg})$ apresentavam um risco duas vezes maior para perda de seguimento ( $>3$ perdas) $(\mathrm{OR}=2,04 ; 1,15-3,62 ; \mathrm{p}=0,015)$. Na análise univariada, no 48 mês do seguimento pós-operatório, apenas a variável mesorregião de procedência esteve associada à perda de seguimento $(p=0,012)$. Conclusão: houve uma perda de seguimento progressiva a partir do segundo ano pós-operatório. Entre os fatores analisados, apenas a variável "excesso de peso" maior do que 49,95kg no pré-operatório esteve associada à perda de seguimento médico-cirúrgico. № 48으ês do período pós-operatório houve uma maior prevalência de perda de seguimento médico-cirúrgico para os pacientes fora do perímetro da cidade do Recife $(51 \%, p=0,052)$.
\end{abstract}

Descritores: Obesidade. Cirurgia Bariátrica. Derivação Gástrica. Perda de Seguimento. 


\section{REFERENCES}

1. NCD Risk Factor Collaboration (NVD-RisC). Trends in adult body-mass index in 200 countries from 1975 to 2014: a pooled analysis of 1698 population-based measurement studies with $19 \cdot 2$ million participants. Lancet. 2016;387(10026):1377-96.

2. Brasil. Ministério da Saúde. Gabinete do Ministro. Portaria n. 424, de 19 de março de 2013. Redefine as diretrizes para a organização da prevenção e do tratamento do sobrepeso e obesidade como linha de cuidado prioritária da Rede de Atenção à Saúde das Pessoas com Doenças Crônicas [portaria na Internet]. Diário Oficial da União 15 abr 2013 [acesso em 12 out 2017];Seção1,(76). Disponível em: http://www. brasilsus.com.br/legislacoes/gm/118324-424.html

3. Brasil. Ministério da Saúde. Portaria n 425, de 19 de março de 2013. Estabelece regulamento técnico, normas e critérios para a Assistência de Alta Complexidade ao Indivíduo com Obesidade. Diário Oficial da União 15 abr 2013 [acesso em 12 out 2017];Seção1,(59). Disponível em: Disponível em: $\quad$ http://www.brasilsus.com.br/legislacoes/ gm/118326-425.html

4. Hörchner R, Schweitzer D. Evaluation of weight loss failure, medical outcomes, and personal experiences after Roux-en-Y gastric bypass: a critical analysis. ISRN Obes. 2013:943423.

5. Farias G, Thieme RD, Teixeira LM, Heyde ME, Bettini SC, Radominski RB. Good weight loss reponders and poor weight loss reponders after Roux-en-Y gastric bypass: clinical and nutritional profiles. Nutr Hosp. 2016;33(5):574.

6. Rosenthal RJ; International Sleeve Gastrectomy Expert Panel, Diaz AA, Arvidsson D, Baker RS, Basso N, et al. International Sleeve Gastrectomy Expert Panel Consensus Statement: best practice guidelines based on experience of $>12,000$ cases. Surg Obes Relat Dis. 2012;8(1):8-19.

7. Ramos AC, Bastos ELS, Ramos MG, Bertin NTS, Galvão TD, Lucena RTF, et al. Resultados a médio prazo com a gastrectomia vertical laparoscópica. ABCD Arq Bras Cir Dig. 2015;28(Supl 1):61-4.

8. Abdeen G, Le Roux CW. Mechanism underling the weight loss and complications of Roux-en-Y gastric bypass. Obes Sug. 2016;26(2):410-21.

9. Khorgami Z, Zhang C, Messiah SE, de la Cruz-Muñoz $N$. Predictors of postoperative aftercare attrition among gastric bypass patients. Bariatr Surg Pract Patient Care. 2015;10(2):79-83.

10. Gourash W F, Ebel F, Lancaster K, Adeniji A, Koozer lacono L, Eagleton JK, MacDougall A, Cassady C, Ericson $\mathrm{H}$, Pories W, Wolfe BM, Belle SH; LABS Consortium Retention Writing Group. Longitudinal Assessment of Bariatric Surgery (LABS): retention strategy and results at 24 months. Surg Obes Relat Dis. 2013;9(4):514-9.

11. Gourash WF, Lockhart JS, Kalarchian MA, Courcoulas $A P$, Nolfi D. Retention and attrition in bariatric surgery research: an integrative review of the literature. Surg Obes Relat Dis. 2016;12(1):199-209.

12. Tess BH, Scabim VM, Santo MA, Pereira JC. Obese patients lose weight independently of nutritional follow-up after bariatric surgery. Rev Assoc Med $\operatorname{Bras}(1992)$. 2015;61(2):139-43.

13. Associação Brasileira para o Estudo da Obesidade e Síndrome Metabólica. Diretrizes brasileiras de obesidade, 2016 [Internet]. $4^{\text {a }}$ ed. São Paulo: ABESO; 2016 [citado 2017 set 01]. Disponível em: http://www.abeso.org.br/uploads/ downloads/92/57fccc403e5da.pdf

14. Sociedade Brasileira de Cirurgia Bariátrica e Metabólica; Colégio Brasileiro de Cirurgioes; Colégio Brasileiro de Cirurgia Digestiva; Sociedade Brasileira de Cirurgia Laparoscópica; Associação Brasileira para o Estudo da Obesidade; Sociedade Brasileira de Endocrinologia e Metabologia. Consenso bariátrico [Internet]. 2008 [citado 2017 set 01] Disponível em: http://www.sbcb.org.br/arquivos/download/ consenso_bariatrico.pdf

15. American College of Surgeons; American Society for Metabolic and Bariatric Surgery. Standards Manual. Resources of optimal care of the Metabolic and Bariatric Surgery Patient 2016 [Internet]. Accessed 2017 Dec 03. Available in: https://www.facs. org/ /media/files/ quality\%20programs/bariatric/ mbsaqip\%20standardsmanual.ashx

16. Vidal P, Ramón JM, Goday A, Parri A, Crous X, Trillo $L$, et al. Lack of adherence to follow-up visits after bariatric surgery: reasons and outcome. Obes Surg. 
2014;24(2):179-83.

17. Jennings N, Boyle M, Mahawar K, Balupuri S, Small P. The relationship of distance from the surgical centre on attendance and weight loss after laparoscopic gastric bypass surgery in the United Kingdom. Clin Obes. 2013;3(6):180-4.

18. Higa K, Ho T, Tercero F, Yunus $T$, Boone KB. Laparoscopic Roux-en-Y gastric bypass: 10-years follow-up. Surg Obes Relat Dis. 2011;7(4):516-25.

19. Moroshko I, Brennan L, O'Brien P. Predictors of attrition in bariatric aftercare: a systematic review of the literature. Obes Surg. 2012;22(10):1640-7.

20. Scabim VM, Eluf Neto J, Tess BH. Adesão ao segmento nutricional ambulatorial pós-cirurgia bariátrica e fatores associados. Rev Nutr. 2012;25(4):497-506.

21. Menegotto ALS, Cruz MRR, Soares FL, Nunes MGJ, Branco Filho AJ. Avaliação da frequência em consultas nutricionais dos pacientes após cirurgia bariátrica. ABCD Arq Bras Cir Dig. 2013;26(2):117-9.

22. Compher CW, Hanlon A, Kang Y, Elkin L, Williams $\mathrm{NN}$. Attendance at clinical visits predicts weight loss after gastric bypass surgery. Obes Surg. 2012;22(6): 927-34.

23. Sockalingam S, Cassin S, Hawa R, Khan A, Wnuk S, Jackson $T$, et al. Predictors of post-bariatric surgery appointment attendance: the role of relationship style. Obes Surg. 2013;23(12):2026-32.

24. McVay MA, Friedman KE, Applegate KL, Portenier DD. Patient predictors of follow-up care attendance in Roux-en-Y gastric bypass patients. Surg Obes Relat Dis. 2013;9(6):956-62.

25. Lara MD, Baker MT, Larson CJ, Mathiason MA, Lambert PJ, Kothari SN. Travel distance, age and sex as factors in follow-up visit compliance in the post-gastric bypass population. Surg Obes Relat Dis. 2005;1(1):17-21.

26. Spaniolas K, Kasten KR, Celio A, Burruss MB, Pories WJ. Postoperative follow up after bariatric surgery: effect on weight loss. Obes Surg. 2016;26(4):900-3.

Received in: 30/01/2018

Accepted for publication: 01/03/2018

Conflict of interest: none.

Source of funding: none.

\section{Mailing address:}

Giselle de Queiroz Menezes Batista Belo

E-mail: leli_belo@yahoo.com.br /

marciavirginiodearaujo@gmail.com

\section{(cc) BY}

